\title{
VILAS FERROVIÁRIAS NO OESTE PAULISTA - UM PATRIMÔNIO INDUSTRIAL EM ÁLVARES MACHADO E SANTO ANASTÁCIO
}

\author{
Mariana Souza Branco, Cristina Maria Perissinotto Baron \\ Universidade Estadual Paulista -UNESP, Curso de Arquitetura e Urbanismo. Presidente Prudente, SP. E-mail: \\ mariana.souza.branco@gmail.com. Agência de fomento: PIBIC - CNPq
}

\section{RESUMO}

A Estrada de Ferro Sorocabana propiciou o surgimento de núcleos urbanos e posteriormente muitas cidades, principalmente no Oeste Paulista. Os municípios de Álvares Machado e Santo Anastácio surgiram a partir da chegada da ferrovia, usada para escoamento de produtos, portanto possui grande valor urbanístico. Com o nascimento de novos núcleos urbanos houve também a construção de um patrimônio arquitetônico: o complexo ferroviário; incluindo suas vilas, que contribuíram para a difusão de um novo modo de vida, cultura e tecnologias. A pesquisa identifica o conjunto de edifícios componentes do complexo ferroviário: Estação Ferroviária, Galpões e Vilas Ferroviárias, sendo o foco principal o estudo das habitações dos trabalhadores da Sorocabana.

Palavras-chave: Patrimônio Industrial, Vilas Ferroviárias, Estrada de Ferro Sorocabana, Oeste Paulista, Santo Anastácio, Álvares Machado.

THE RAILWAY BUILDINGS SET OF THE WEST SIDE OF SÃO PAULO'S STATE: THE RELEVANCE OF THE RAILWAY INDUSTRIAL WORKER'S VILLAGES FOR THE FORMATION OF THE CITIES ÁLVARES MACHADO AND SANTO ANASTÁCIO

\begin{abstract}
The Sorocabana Railway provided the emerging of urban cores and later many cities, manly in the west side of the state of São Paulo. The cities of Álvares Machado and Santo Anastácio emerged of the arrival of the railway, used as drainage of products, therefore it has great urban value. Among the creation of urban cores there was also the construction of an architectural heritage such as the railway buildings set, including the worker's villages, which cooperated for the spread of a new life style, culture and technology. This research identifies the set of buildings constituent of the railway set, such as Train Station, Sheds and Worker's Villages, but the main focus is the study of the Sorocabana workers' house.

Keywords: Industrial Heritage, Railway Industrial Worker's Villages, Sorocabana Railway, West of São Paulo, Santo Anastácio, Álvares Machado.
\end{abstract}

\section{INTRODUÇÃO}

O "Vale do Paranapanema" (região que abrange Sorocaba e Botucatu até o Rio Paraná) no século XIX era ocupada apenas por índios (AVILA JUNIOR, 1995), situação que se manteve até a implantação da ferrovia pela Companhia Sorocabana, fundada em 1872, e concluída em 1879, que se uniu a Companhia Ituana em 1892. A Estrada de Ferro Sorocabana foi um dos principais responsáveis pela ocupação do Oeste Paulista, em conjunto com a introdução da cultura do café. Sua linha tronco expandiu-se e chegou a Presidente Prudente em 1919 e a Presidente Epitácio, às margens do rio Paraná seu ponto final - em 1922, passando por Álvares Machado (primeiramente conhecido como "Brejão") em 1919 (concomitantemente com Presidente Prudente) e por Santo Anastácio em 1920. (ABREU, 1972).

O surgimento desses novos núcleos urbanos se deu pela implantação da estação ferroviária, em conjunto com galpões e suas vilas ferroviárias: habitações construídas pela ferrovia para seus trabalhadores, possuindo tipologias 
variadas e hierárquicas, dependendo com a função desenvolvida por seu primeiro proprietário.

As vilas ferroviárias são patrimônio cultural e industrial, e foram implantadas inicialmente na Europa no século XIX como núcleos fabris, para os trabalhadores morarem perto de seu local de seu serviço e suprir parte da demanda por moradia pós revolução indústria, continha também caráter paternalista, com a ideia de calar greves e impor regras ao cotidiano operário. (GUAZZELLI, 2014). Porém no Brasil a ideia principal das vilas e do complexo ferroviário era a urbanização da região, pois em muitas cidades em que a linha do trem chegava - como as do interior paulista - não havia infraestrutura básica. (MORAIS, 2002).

O objetivo geral desse estudo foi estudar como ocorreu a implantação destes conjuntos ferroviários e qual a sua importância para desenvolvimento econômico desta região, identificando o conjunto de edifícios do complexo ferroviário de Santo Anastácio e Álvares Machado: Estação Ferroviária, Galpões e Vila Ferroviária, sendo esse último o foco principal, reconhecendo e registrando o Patrimônio Histórico e Arquitetônico e resgatando a memória ferroviária a partir das moradias e da visão dos trabalhadores da Estrada de Ferro Sorocabana.

\section{METODOLOGIA}

A pesquisa se estruturou em três fases. $\mathrm{Na}$ primeira fase houve revisão bibliográfica sobre o tema e levantamento do material iconográfico e documental do conjunto ferroviário dos Municípios de Alvares Machado e Santo Anastácio.

$\mathrm{Na}$ segunda fase ocorreu levantamento de campo, in loco, do conjunto que ainda permanece na paisagem da cidade $e$ as intervenções que foram realizadas no complexo ferroviário (conjunto formado pela estação ferroviária, galpões, moradias e esplanada).

$\mathrm{Na}$ terceira fase concentrou-se na moradia dos trabalhadores, identificando-os; classificando as tipologias habitacionais e selecionando uma unidade de cada tipologia para realização de estudos, tem por objetivo registrar fisicamente as moradias originais, uma vez que essas construções são aquelas que mais sofrem alterações, para que possam permanecer na memória da população.

\section{RESULTADOS}

O município de Álvares Machado era inicialmente conhecido como "Brejão", surgiu em 1916 como um pequeno povoado com forte presença migratória japonesa e contém atualmente 24651 habitantes. Após a chegada da EFS em 1919 (um mês e meio depois da abertura da estação de Presidente Prudente) seu nome foi alterado.

O complexo ferroviário se encontra a leste da cidade, na estrada Arthur Boigues Filho, via de grande movimento por ser uma das entradas da cidade que liga Álvares Machado a Presidente Prudente. Atualmente há presença da estação ferroviária original, um galpão e a vila ferroviária contendo quatro casas (sendo duas geminadas) em frente à estação e três ao lado (figura 1 e 2).

Figura 1. Complexo original de Álvares Machado, em 1966

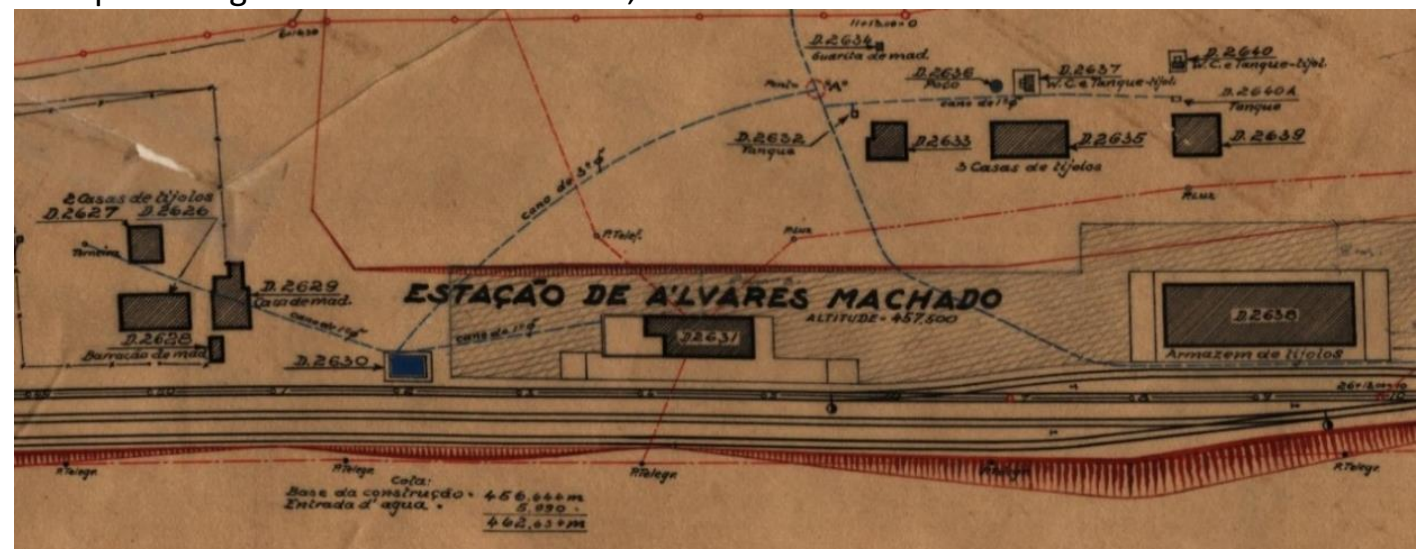

Fonte: Escritório da Inventariança da Rede Ferroviária Federal S.A. de São Paulo. ${ }^{1}$

\footnotetext{
${ }^{1}$ Mapas cedidos pelo Escritório da Inventariança da Rede Ferroviária Federal S.A. de São Paulo, localizado em São Paulo, capital.
} 
Figura 2. Complexo ferroviário em Álvares Machado, em 2017

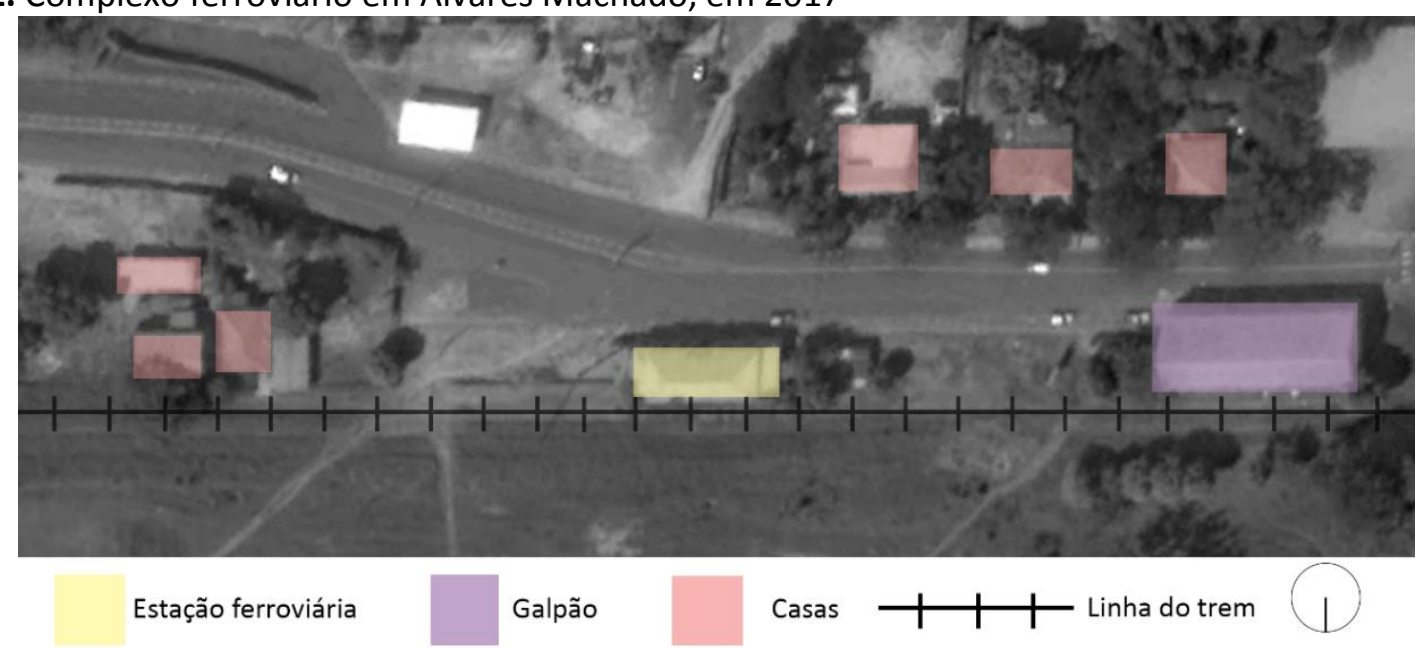

Fonte: As Autoras.

A estação ferroviária foi construída em 1921, em estilo neocolonial (figura 3), porém atualmente ela se encontra extremamente abandonado e deteriorado (figura 4). 0 galpão é datado de 1919, utilizado originalmente para armazenamento de mercadorias e tijolos.

Figura 3. Estação Ferroviária de Álvares Machado, 2017.

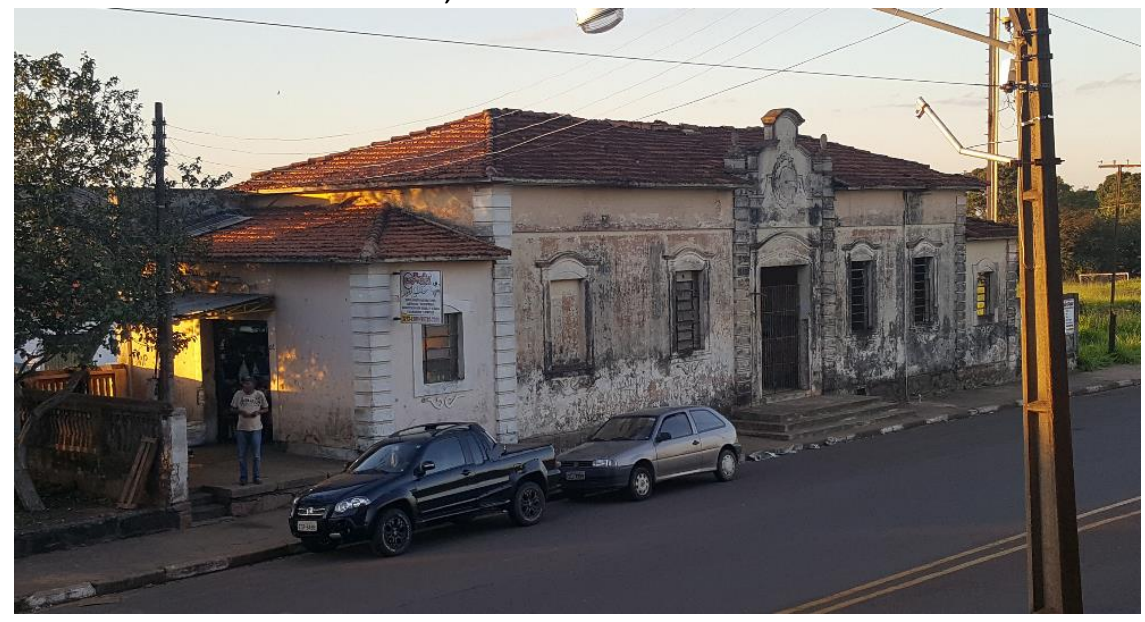

Fonte: As Autoras.

Figura 4. Estação Ferroviária de Álvares Machado, 2017.

Fonte: As Autoras.

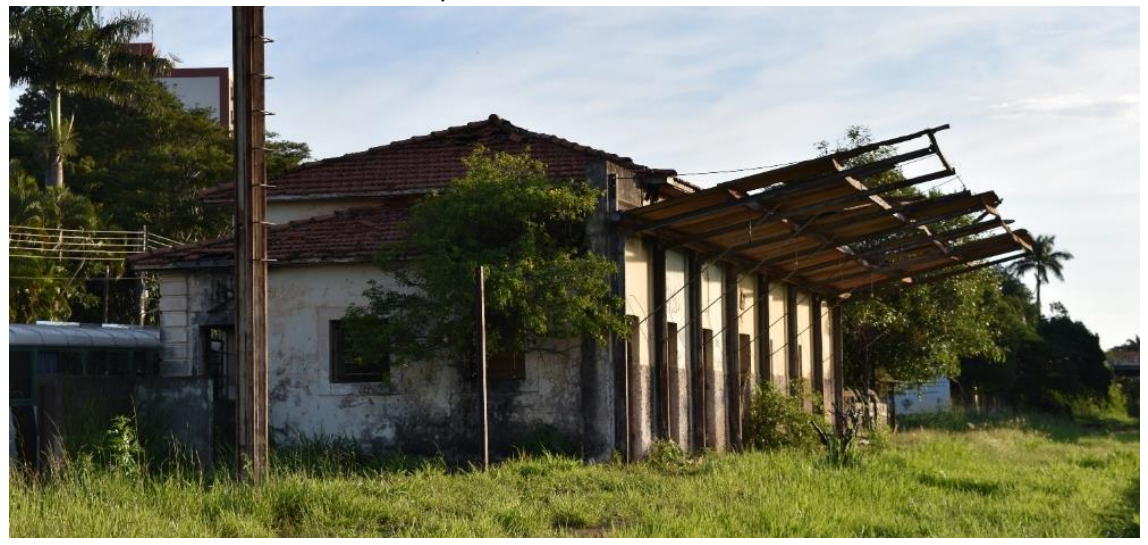

Santo Anastácio - diferente de Álvares Machado onde já havia um povoado inicial - teve sua estação ferroviária instaurada em uma região antes habitada apenas por índios. A cidade 
contém atualmente 20475 habitantes e seu projeto começou em 1917. Sua primeira denominação foi "Vai e Vem", pois foram encontradas dificuldades técnicas para o avanço da ferrovia até a cidade - havia grande volume de terra a ser escavado, um desafio aos equipamentos da época. A equipe precisou procurar rotas alternativas e devido as inúmeras idas e voltas o município ficou conhecido (não oficialmente) como "Vai e Vem", e teve seu nome modificado para Santo Anastácio em sua inauguração em 1920 , devido ao rio próximo as suas terras. (AVILA JUNIOR, 1995)

A cidade teve três estações ferroviárias ao longo de sua história. A primeira é datada de
1920, em 1927 a cidade ganhou um novo edifício - edificado no local onde está o atual prédio - e em 1939 este foi substituído pelo atual. Por conta da mudança de lados da estação ferroviária há duas diferentes localizações das casas dos trabalhadores das ferrovias, havendo habitações do lado original da estação e do lado atual.

A estação ferroviária atual foi projetada pelo arquiteto Antônio Arantes Monteiro e executada pela Construtora Azevedo \& Travassos e é um exemplo de construção Art Déco, contendo também características modernas na sua plataforma (figura 5).

Figura 5. Estação ferroviária e sua plataforma

Fonte: As Autoras.

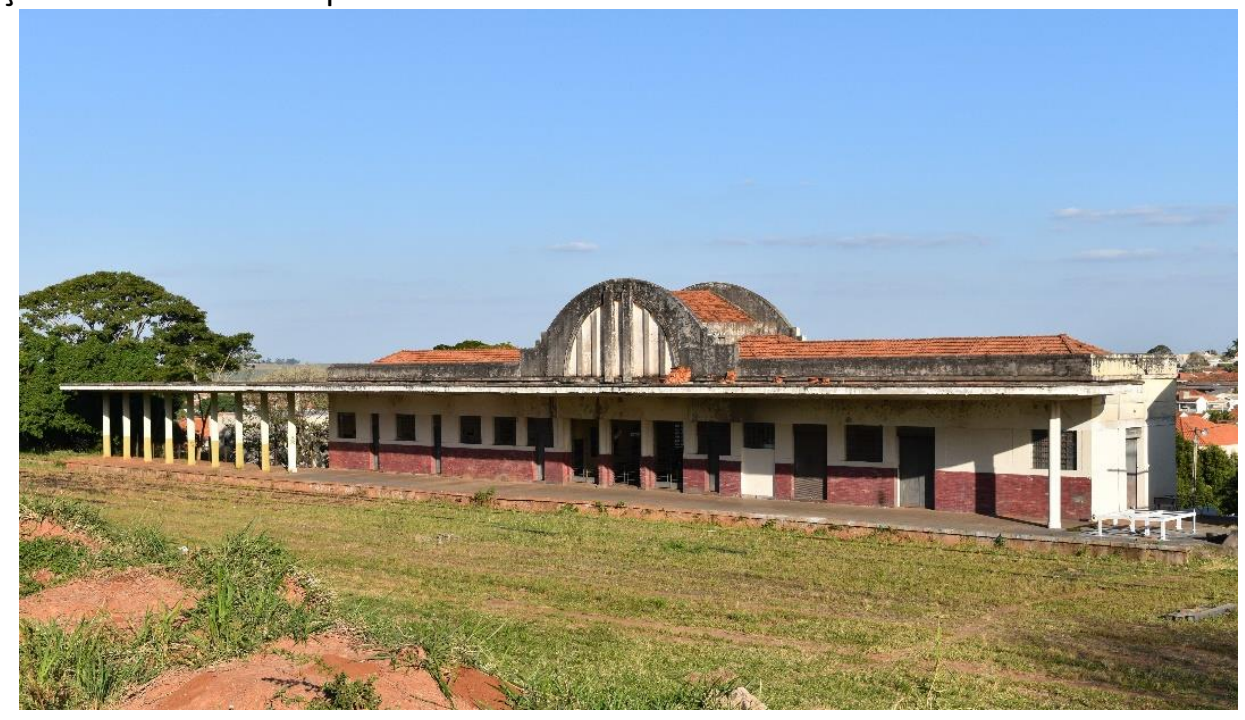

A vila ferroviária continha originalmente vinte e cinco casas, cinco ao lado da atual estação e vinte atrás da estação. Contém também um galpão ao lado da estação, como pode ser observado na figura 6. Grande parte dos terrenos das casas foram ocupados, e muitas casas demolidas, comparando a figura 7 e 8 pode-se analisar como poucas casas sobreviveram no complexo em 2002 e como novas casas foram construídas nos terrenos das antigas casas em 2016.

Figura 6. Complexo original de Santo Anastácio, em 1966.

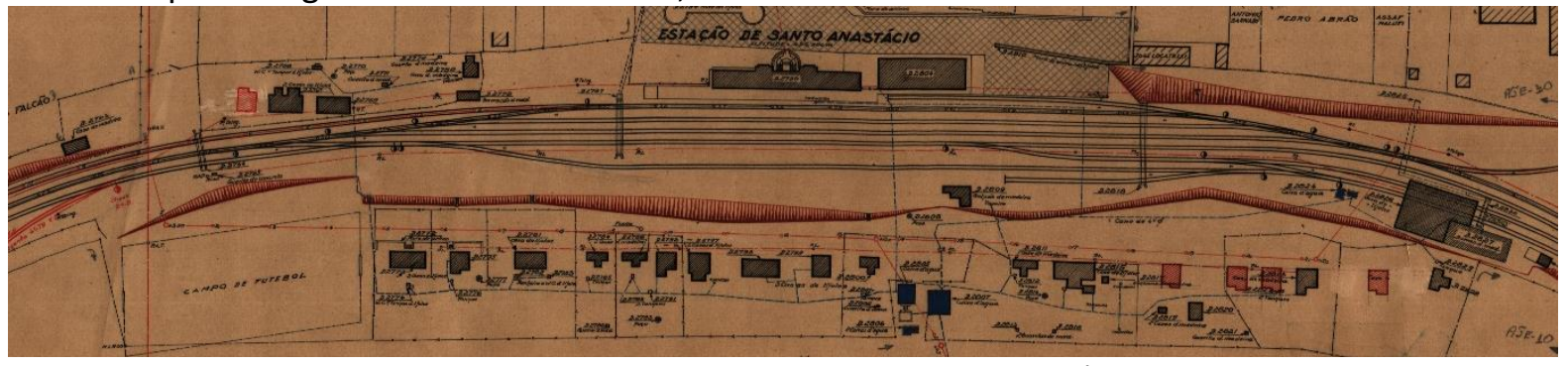

Fonte: Escritório da Inventariança da Rede Ferroviária Federal S.A. de São Paulo. ${ }^{1}$ 
Figura 7. Situação do complexo em 2002.

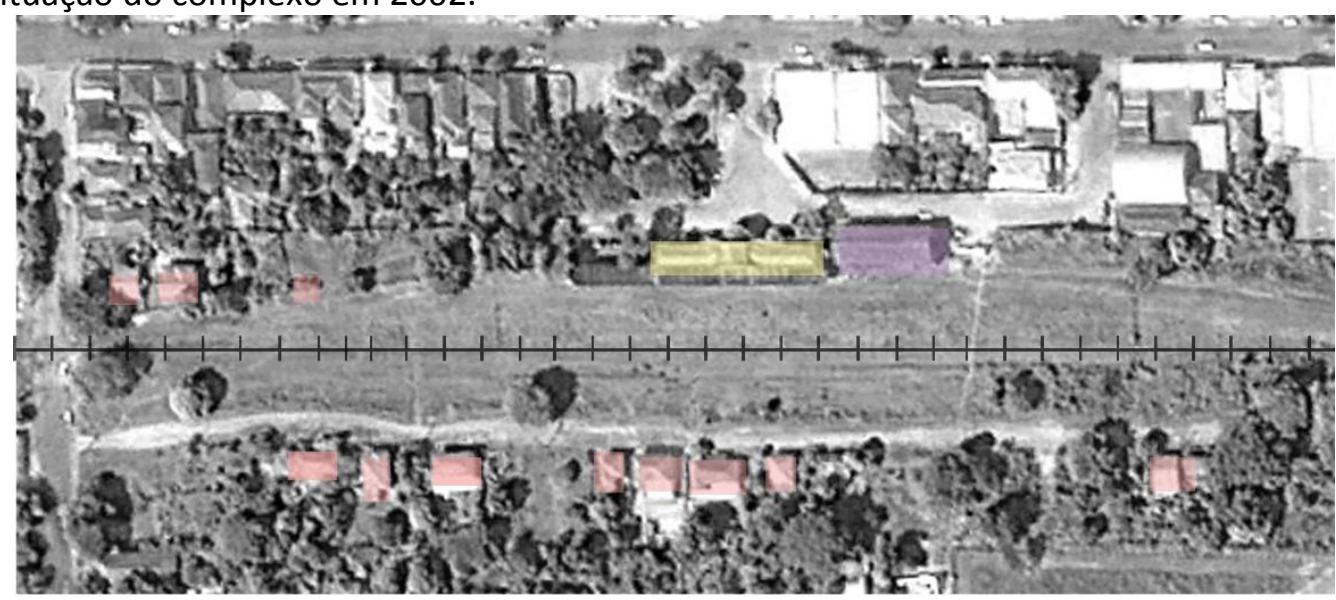

Estação ferroviária Galpão $\quad$ Casas

Fonte: As Autoras.

Figura 8. Situação do complexo em 2016.

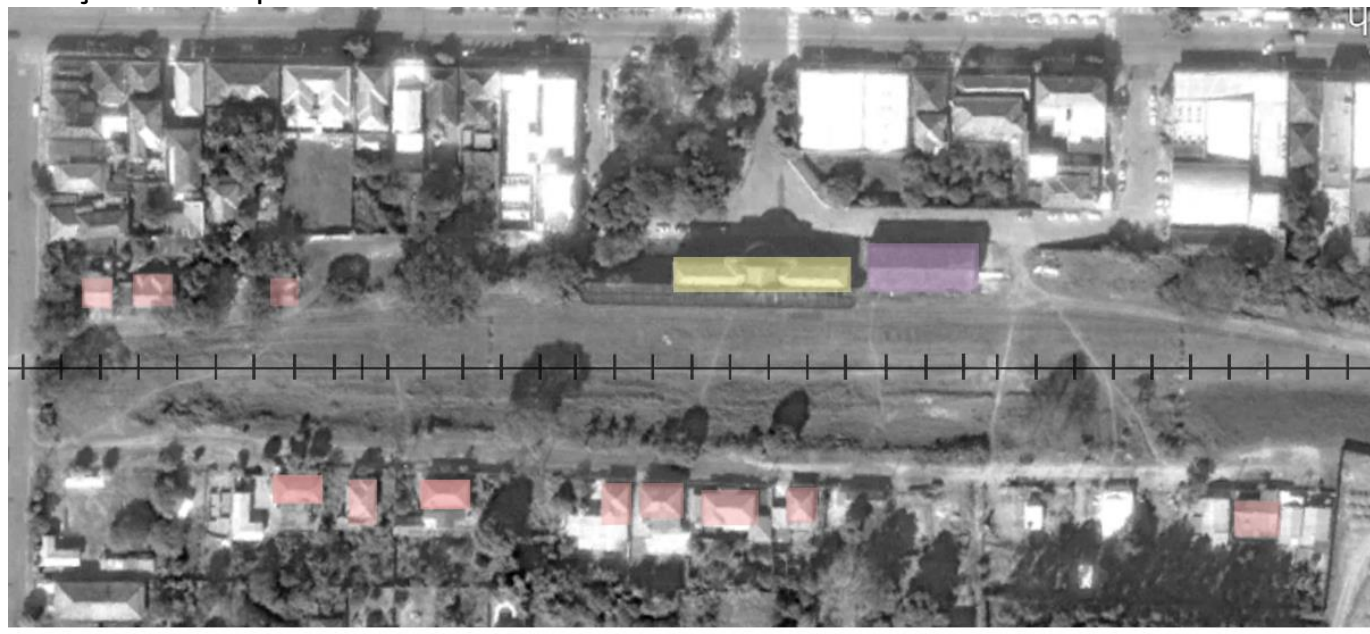

Estação ferroviária

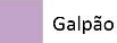

Casas

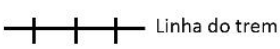

Fonte: As Autoras.

As habitações seguem uma hierarquia, mudando de tipologia, tamanho e material de acordo com a função de seu morador original. Em Álvares Machado originalmente apenas uma casa era de madeira, e em Santo Anastácio sete, sendo o restante de tijolos - para incentivar à construção em alvenaria, a prefeitura isentava de impostos seus proprietários. (BARON, LOPES, [2014?])

As casas visitadas contêm número de patrimônio, inseridos pela E.F.S. e posteriormente pela FEPASA (Ferrovia Paulista S.A.), alguns já apagados pelo tempo (figura 9 e 10). As habitações em ambas cidades seguem um padrão, contendo originalmente sala, dois quartos, cozinha e banheiro localizado na área externa da casa, mudando entre si de tamanho e layout e materiais semelhantes, com tijolo aparente, madeira nos pisos e forros, e grandes portas e janelas também em madeira. 
Figura 9 e 10. Número de patrimônio nas casas em Álvares Machado

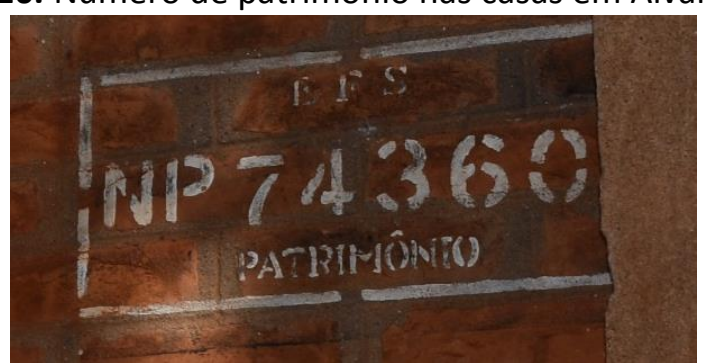

Fonte: As Autoras.

Os tijolos utilizados nas casas possuem uma marca escrita "EFS" (como pode ser observado na figura 11), contém $30 \times 15 \mathrm{~cm}$, sendo que as paredes externas têm $30 \mathrm{~cm}$ e as internas $15 \mathrm{~cm}$. O pé direito alto é também uma

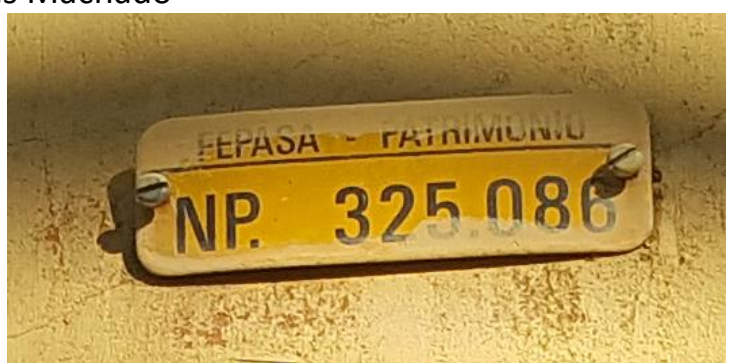

característica das casas, em ambas cidades ele mede 4,5m. O ferro dos trilhos da ferrovia se mostraram presente também nas residências de forma não usual, exercendo função de pilares e vigas para a caixa d'água, como visto na figura 12 .

Figura 11 e 12. Caixa d'agua, utilizando trilhos como estrutura e tijolo original da residência.
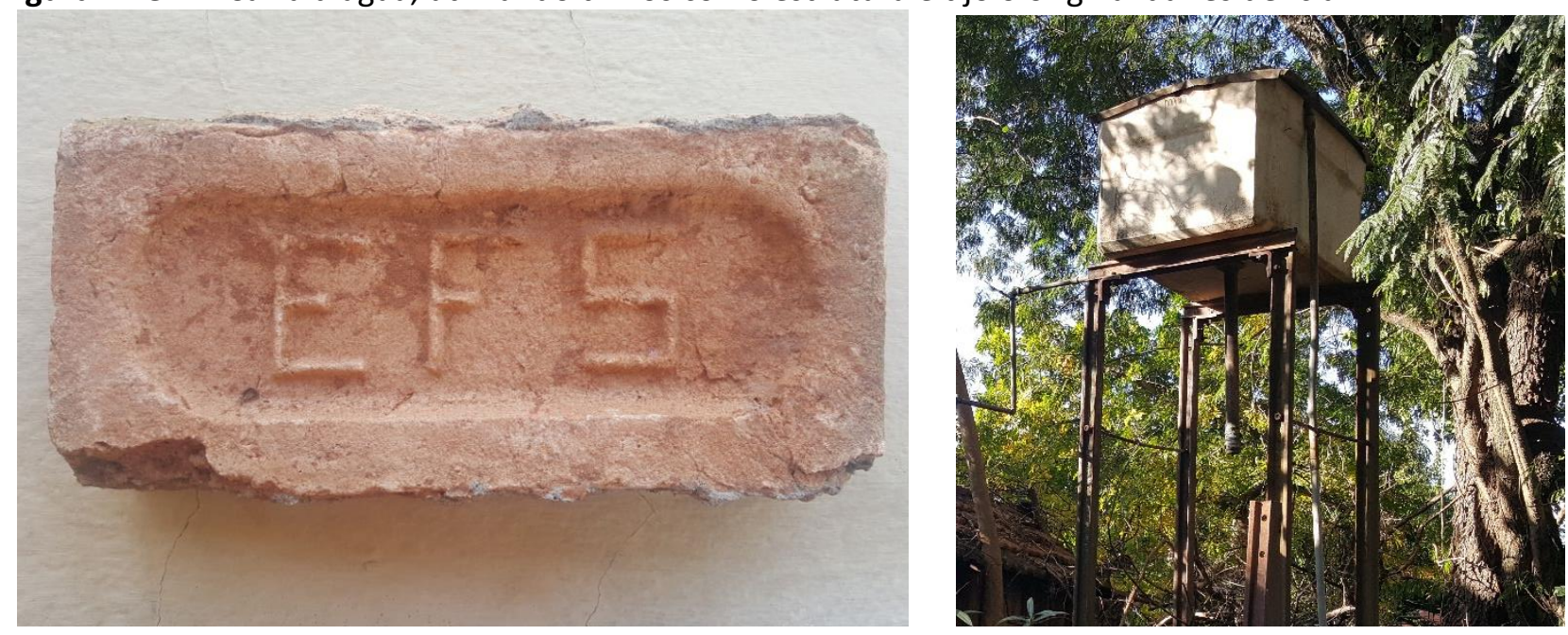

Fonte: As Autoras.

As casas nas quais os moradores originais possuíam funções mais "elevadas" no trabalho da ferrovia possuem certa ornamentação no entorno de portas e janelas. Em relação a implantação, as casas são isoladas no lote, contendo poucos exemplos de casas geminadas. $O$ terreno de todas é retangular e extenso, contendo aproximadamente $20 \times 40 \mathrm{~m}$ em Álvares Machado e $30 \times 40 \mathrm{~m}$ em Santo Anastácio.

Em Álvares Machado a maior casa hoje funciona como viveiro de plantas, e apresenta certa conservação na parte externa, mas deteriozação da parte interna. Nota-se que houve modificação da casa ainda no século XX, com a inserção de banheiro no espaço interior da casa e uma cozinha mais ampla. Essas intervenções são notáveis pela inserção desse anexo por causa da espessura das paredes externas e internas, uma das paredes foi inserida em cima de um dos ornamentos das janelas originais (figura 13) e seu pé direito é inferior ao do "núcleo" original da casa. Sabe-se ainda que esse intervenção foi ainda daquela época pois o piso de ladrilho do novo banheiro é igual ao da estação ferroviária. $\mathrm{Na}$ figura 14 é notável sua fachada, com ornamentação e grandes janelas, e na figura 15 planta baixa - pode-se perceber as modificações da casa. 
Figura 13. Expansão da casa em seu lado direito, com telhado em cima do ornamento.

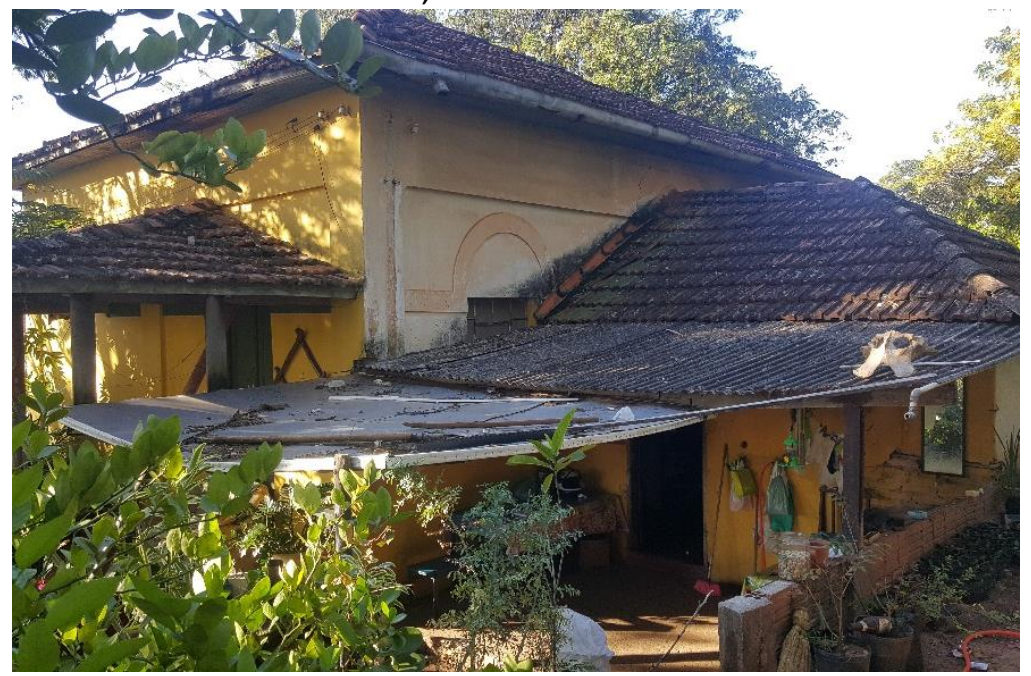

Fonte: As Autoras.

Figura 14 e 15. Fachada da casa mais ampla de Álvares Machado
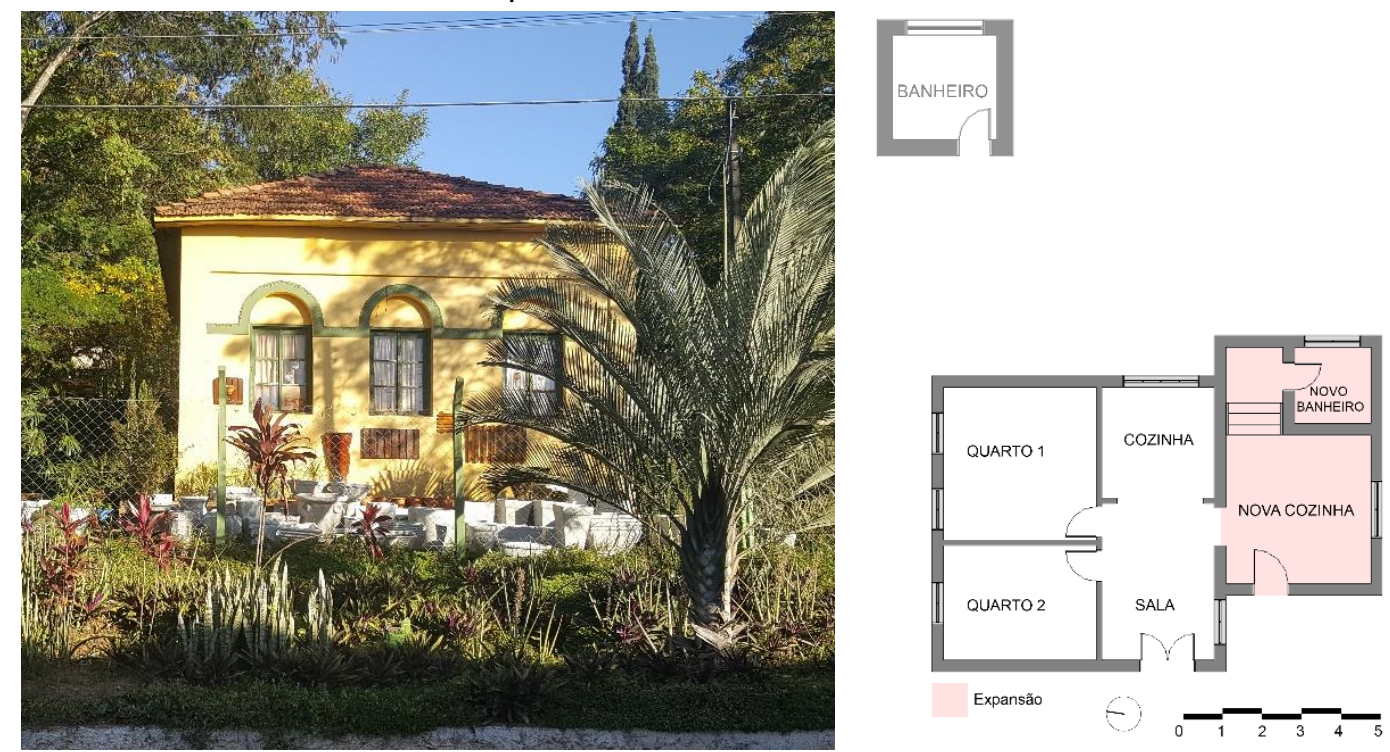

Fonte: As Autoras.

Já em Santo Anastácio, a maior casa e que se encontra em bom estado de conservação é habitada por um antigo ferroviário desde 1985. A casa foi modificada para atender as demandas da família, aumentando sua cozinha, adicionando dispensas e banheiro no interior da casa, como pode ser observado na figura 16 e 17 . Ela também possui certa ornamentação e grandes janelas - originalmente de madeira - que foram modificadas e substituídas por janelas de alumínio (figura 18). 
Figura 16 e 17. Planta baixa de residência em Santo Anastácio.
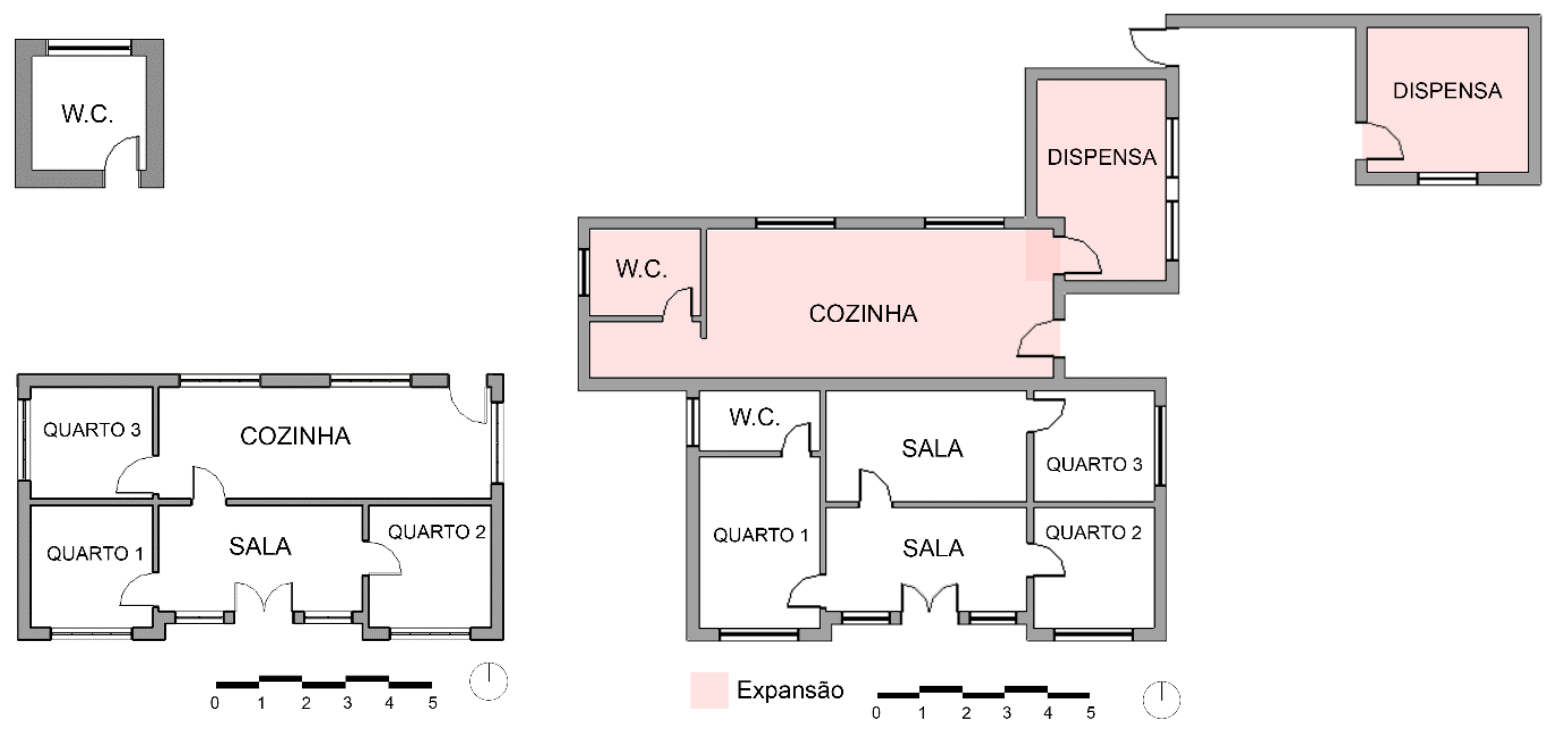

Fonte: As Autoras.

Figura 18. Fachada da residência em Santo Anastácio

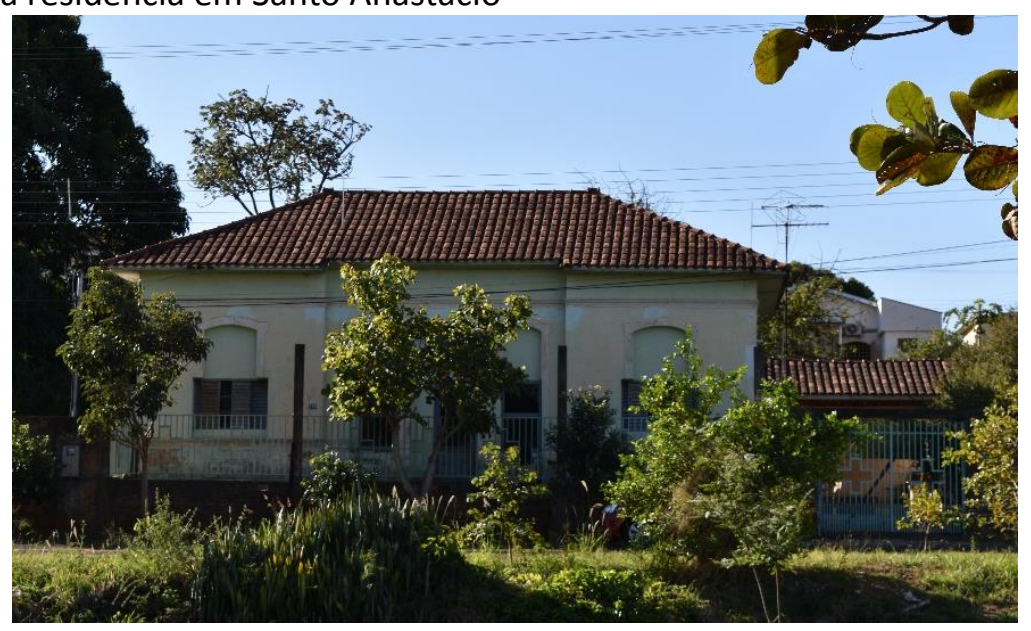

Fonte: As Autoras.

\section{DISCUSSÃO}

O complexo ferroviário de Álvares Machado e Santo Anastácio apresentam diferença de tamanho e suas estações possuem estilos arquitetônicos diferentes, porém as semelhanças entre eles são notáveis. A situação de ambas se encontra a mesma: abandono. As estações ferroviárias se encontram fechadas e abandonadas, os galpões hoje exercem uso particular (ambos são serralherias, serviço que pode ajudar a acelerar sua deterioração), e as casas se apresentam modificadas, algumas abandonadas em Álvares Machado e muitas foram demolidas em Santo Anastácio.

As residências são os edifícios que mais sofreram modificações, decorrentes do próprio tempo de construção e da vida útil das unidades, como também das modernizações e transformações das estruturas familiares. Apesar das modificações observadas, ainda é possível identificar algumas construções originais, como também, famílias descendentes dos ferroviários que trabalharam para a Sorocabana. Resgatar esta história através da identificação do conjunto arquitetônico como um todo significa manter viva a memória ferroviária.

Com esse modelo de habitação a mão de obra estava sempre próxima ao seu local de trabalho (sendo a vila uma extensão dele), e exerceu papel de mudança de hábitos - o surgimento das linhas de trem e vilas ferroviárias é concomitante a abolição da escravatura e revolução industrial - pois a organização das vilas ajudava na manutenção da ordem e disciplina, e distanciava os trabalhadores cada vez mais dos antigos hábitos rurais. (CORREIA, 2004). As companhias destinaram parte de seus recursos construindo unidades habitacionais próximas a 
estação ferroviária e a própria ferrovia, como uma forma de viabilizar a operacionalização de suas linhas e garantir seu funcionamento 24 horas por dia.

Atualmente em Álvares Machado as casas são habitadas por parentes de ferroviários e terceiros, ao lado da estação as casas se encontram abandonadas. Em Santo Anastácio boa parte das casas foram demolidas e/ou extremamente modificadas, foram reconhecidos dois moradores originais - um ferroviário e viúva de ferroviário - e as outras casas são habitadas por terceiros. Houve certa resistência na aproximação com alguns moradores pela questão da propriedade e posse do imóvel, o que dificultou no registro das habitações.

As vilas ferroviárias não são comumente reconhecidas como patrimônio, assim como boa parte do complexo ferroviário. O conceito de "patrimônio industrial" surgiu apenas na década de 50, e se difundiu após a demolição de importantes prédios da arquitetura industrial. A arquitetura industrial engloba não apenas edificações construídas para industrias, a partir dos anos 60 houve ampliação do que é considerado patrimônio histórico, incluindo também ambientes urbanos e rurais, arquiteturas vernaculares e construções recentes, restantes do patrimônio industrial (KÜHL, 1998).

\section{CONCLUSÃO}

A configuração do Oeste Paulista está diretamente ligada a importância do sistema ferroviário para o nascimento e expansão de suas cidades, sendo de fundamental importância o resgate da paisagem inicial dos núcleos urbanos e o registro atual. A história dos municípios de Álvares Machado e Santo Anastácio é intrínseca com o surgimento da ferrovia e do núcleo urbano a partir da casa dos trabalhadores, mas a história dos municípios do Oeste Paulista é pautada na perspectiva dos coronéis e "desbravadores", mas a história dos trabalhadores que ajudaram a fundar as cidades é esquecida.

As Vilas Ferroviárias foram indutoras de uma nova forma de moradia, surgiram no Brasil como um dos primeiros modelos de habitação planejada e racional, deixando os velhos hábitos rurais de lado. A preservação do complexo ferroviário e das vilas e seu reconhecimento como patrimônio desta região é essencial, mantendo viva a memória dos primeiros habitantes, a história política da cidade e os aspectos sociais da época.

\section{REFERÊNCIAS}

$A B R E U, D$. S. Formação histórica de uma cidade pioneira paulista. Presidente Prudente: Faculdade de Filosofia, Ciências e Letras de Presidente Prudente, 1972.

AVILA JUNIOR, C. J. Santo Anastácio: história de uma cidade. Santo Anastácio: [s.n.], 1995.

BARON, Cristina M. P.; LOPES, Pedro H. As vilas ferroviárias de Presidente Prudente - SP. In: CONGRESSO INTERNACIONAL DE REABILITAÇÃO DO PATRIMÔNIO ARQUITETÔNICO E EDIFICADO, 12., 2014, Bauru. Anais... [S.I.]: [s.n.], [2014?].

CORREIA, Telma de B. A Construção do habitat moderno no Brasil: 1870-1950. São Carlos: RiMa, 2004.

GUAZZELLI, Barbara Gonçalves. Ferrovia, trabalho e habitação: vilas operárias de Campinas (1883-1919). 2014. Dissertação (Mestrado em Arquitetura e Urbanismo) Instituo de Arquitetura e Urbanismo, Universidade de São Paulo, São Carlos, 2014.

KÜHL, Beatriz M. Arquitetura do ferro e arquitetura ferroviária em São Paulo: reflexões sobre sua preservação. São Paulo: Ateliê Editorial; FAPESP, 1998.

MORAIS, Marcelo. As vilas ferroviárias paulistas: a arquitetura e as relações urbanas nos núcleos habitacionais ferroviários. 2002. Dissertação (Mestrado) - Universidade de São Paulo, 2002

Recebido para publicação em 09/08/2017

Revisado em 15/09/2017

Aceito em 19/09/2017 